\title{
Effect of Different Cooking Methods on Histamine Levels in Selected Foods
}

\author{
Bo Young Chung*, Sook Young Park*, Yun Sun Byun, Jee Hee Son, Yong Won Choi, Yong Se Cho, \\ Hye One Kim ${ }^{\dagger}$, Chun Wook Park ${ }^{\dagger}$ \\ Department of Dermatology, Hallym University Kangnam Sacred Heart Hospital, Hallym University College of Medicine, Seoul, Korea
}

Background: Histamine in food is known to cause food poisoning and allergic reactions. We usually ingest histamine in cooked food, but there are few studies about the influence of cooking method on the histamine level. Objective: The purpose of this study was to determine the influence of cooking methods on the concentration of histamine in foods. Methods: The foods chosen were those kinds consumed frequently and cooked by grilling, boiling, and frying. The histamine level of the food was measured using enzyme-linked immunosorbent assay. Results: Grilled seafood had higher histamine levels than raw or boiled seafood. For meat, grilling increased the histamine level, whereas boiling decreased it. For eggs, there was not much difference in histamine level according to cooking method. Fried vegetables had higher histamine levels than raw vegetables. And fermented foods didn't show much difference in histamine level after being boiled. Conclusion: The histamine level in food has changed according to the cooking method used to prepare it. Frying

Received September 9, 2016, Revised February 21, 2017, Accepted for publication March 8, 2017

*These authors have equally contributed to the article as co-first authors.

${ }^{\dagger}$ These authors have equally contributed to the article as co-corresponding authors.

Corresponding author: Hye One Kim, Department of Dermatology, Hallym University Kangnam Sacred Heart Hospital, 1 Singil-ro, Yeongdeungpo-gu, Seoul 07441, Korea. Tel: 82-2-829-5221, Fax: 82-2-832-3237, E-mail: hyeonekim@gmail.com

Chun Wook Park, Department of Dermatology, Hallym University Kangnam Sacred Heart Hospital, 1 Singil-ro, Yeongdeungpo-gu, Seoul 07441, Korea. Tel: 82-2-829-5221, Fax: 82-2-832-3237, E-mail: dermap@ daum.net

This is an Open Access article distributed under the terms of the Creative Commons Attribution Non-Commercial License (http://creativecommons. org/licenses/by-nc/4.0) which permits unrestricted non-commercial use, distribution, and reproduction in any medium, provided the original work is properly cited.

Copyright (c) The Korean Dermatological Association and The Korean Society for Investigative Dermatology and grilling increased histamine level in foods, whereas boiling had little influence or even decreased it. The boiling method might be helpful to control the effect of histamine in histamine-sensitive or susceptible patients, compared with frying and grilling. (Ann Dermatol 29(6) 706 714, 2017)

\section{-Keywords-}

Biogenic amines, Food, Histamine

\section{INTRODUCTION}

Food-derived histamine is associated with non-allergic food intolerance and food poisoning, whereas endogenous histamine stored in mast cells is responsible for food allergy reactions ${ }^{1}$. At high concentrations, they are risk factors for food intoxications, whereas moderate levels, may lead to food intolerance ${ }^{2}$. Histamine intolerance and poisoning resulted from the disequilibrium of accumulated histamine and the capacity for histamine degradation by the enzyme diamine oxidase $(\mathrm{DAO})^{3-5}$. Ingested histamine can be metabolized by DAO, which is mainly present in intestinal epithelial cells ${ }^{5,6}$. If we ingest excessive histamine, un-degraded histamine could be absorbed into the body. Impaired histamine degradation based on reduced DAO activity, and the resulting excess of histamine, may cause numerous symptoms mimicking an allergic reaction ${ }^{1}$. There are some concrete clinical examples of reduced DAO activity including the subgroup of patients those with atopic dermatitis ${ }^{7}$, that are pregnant ${ }^{8}$, and other chronic disease (e.g., liver cirrhosis ${ }^{9}$, anorexia nervosa ${ }^{10}$, inflammatory bowel disease: ulcerative colitis and Crohn's disease $^{11}$ ), and those that use anticancer drugs ${ }^{12}$. Even the abundance of histamine is not the only causative factor for food allergy, there are some evidences which address 
higher levels of histamine-containing food could induce more adverse reaction than lower levels of histamine-containing food in susceptible patients ${ }^{5,7,8,13}$.

Various approaches, such as modified atmosphere packaging, irradiation, high hydrostatic pressure, and food additives and preservatives have been applied to control the accumulation of histamine in food products ${ }^{14}$. These methods of controlling histamine content rely mainly on growth inhibition of histamine-producing bacteria and histamine decarboxylase activities ${ }^{15}$.

There are many reports regarding the histamine content in raw food ${ }^{2,16-18}$. High histamine levels are found in food such as tuna, mackerel, anchovy, spinach, wine, cheese, sausage and fermented foods ${ }^{2,18}$. However, there are few reports regarding the histamine content in cooked food and the influence of cooking methods. Because we eat cooked food more often than raw, we need to know how cooking methods influence histamine level. To determine the influence of cooking method on the concentration of histamine, we started with a list of foods rich in histamine; then compared the histamine level of these foods when raw, and after household processing (e.g., frying, grilling and boiling).

\section{MATERIALS AND METHODS}

\section{Foods}

Because there are numerous food items, the most commonly eaten foods were given priority. Twenty-seven foods often consumed by Koreans were selected for this study. We got help determining representative food items by consultation with those from the Department of Nutrition at Hallym University Kangnam Sacred Heart Hospital, Hallym University College of Medicine. These were categorized as 1) fishery products and processed marine products, 2) meat, processed meat, and eggs, 3) vegetables, 4) fermented pastes and dairy products (milk and cheese). The detailed foods list is presented in Table 1. Processed marine products included canned tuna (Light Tuna Can;
Dongwon, Seoul, Korea) and processed meat included sausage (a mixture of $19 \%$ pork and $64 \%$ chicken, Bek-Sul Kentucky Frank; Cheiljedang, Seoul, Korea), and ham (pork only, Spam; Cheiljedang). Fermented foods were bought; soybean paste (Chamdoenjang; Pulmuone, Seoul, Korea), red pepper paste (Haechandeul Taeyangcho gold red pepper paste; Cheiljedang), salty fermented anchovies (Haechandeul Haseonjeong fermented anchovy; Cheiljedang), and Kimchi with cabbage (Pulgipeun taste Junlado Kimchi; Pulmuone), Kimchi with radish (Pulgipeun taste Junlado Kkakdugi; Pulmuone) and the cheese was hard, sliced cow cheese (de Vinch; Namyang, Seoul, Korea). These foods were all bought at local hypermarket on the day of experiment (E-mart Yeouido, Seoul, Korea).

\section{Cooking methods}

We gave priority to the cooking methods most commonly used by Koreans, including boiling, grilling, and frying. When selecting representative cooking methods, we also got help and consultation from the same nutrition department. The foods were cooked by boiling, grilling, and frying. Because the histamine concentration is also dependent on the freshness of food, the foods were cooked immediately after purchase. Before cooking, all the raw foods were prepared by cutting into 1-g portions. The cooking temperature was monitored continuously using thermocouples.

Boiling was conducted at $90^{\circ} \mathrm{C}$ for $5 \sim 10$ minutes in a water bath $(500 \mathrm{ml})$. Distilled water was also $90^{\circ} \mathrm{C}$ when it was boiled in aluminum foil cups. Grilling was performed at $150^{\circ} \mathrm{C}$ in a preheated pan for $1 \sim 5$ minutes without oil. Fishery products and processed marine products, eggs, meat and processed meat were grilled, or boiled until well done. For frying, fresh soy bean oil $(10 \mathrm{ml})$ was used. Dried anchovy, eggs, onions, carrots, and laver seaweed were fried at $150^{\circ} \mathrm{C}$ for $1 \sim 5$ minutes in a preheated pan. Spinach was blanched for 30 seconds at $90^{\circ} \mathrm{C}$ in aluminum foil cups.

The laboratory room temperature was controlled to $25^{\circ} \mathrm{C}$.

Table 1. Food items in our study

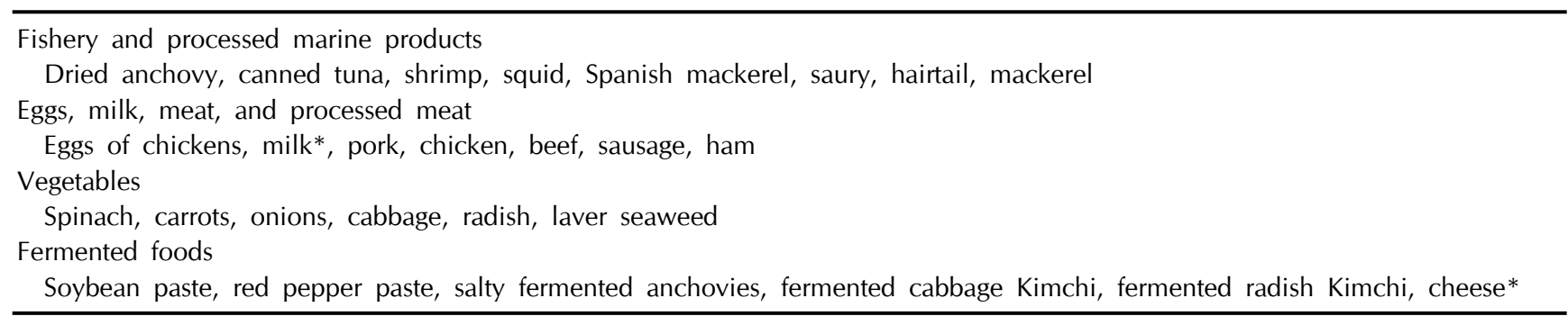

*Daily product (milk and cheese). 
The laboratory workplace guidelines for humidity are $40 \%$ $60 \%$. All our experiments were done under these conditions.

\section{Histamine measurements}

Before cooking, 30 gram samples of each fresh foods (dried anchovy, tuna in can, shrimp, Spanish mackerel, saury, hairtail, mackeral, pork, chicken, beef, sausage, ham, egg, onion, carrot, spinach, laver seaweed, cabbage, radish, soy bean paste, red pepper paste, salty fermented anchovies, Kimchi, fresh milk and cheese) were ground in a mixer (SFM-656CS; Shinil Industry, Seoul, Korea) for measurement of histamine level, respectively. After cooking, same method was done for each material to check histamine level. For each test, $1 \mathrm{~g}$ of food was homogenized with $5 \mathrm{ml} 0.1 \mathrm{M} \mathrm{HCl}$ in a mixer for $5 \mathrm{~min}$. The homogeneous samples were further centrifuged for $10 \mathrm{~min}$ at $3,000 \times g$. Then, $500 \mu \mathrm{l}$ of samples were mixed with 500 $\mu \mid$ of diluents (phosphate buffer saline) to reduce matrix interference. The histamine assay of each diluted food sample was performed with histamine enzyme-linked immunosorbent assay (ELISA) kit (Cat no. 5133-8; Diagnostic Automation, Inc., Calabasas, CA, USA). The instructions for this ELISA kit are based on detection of histamine only for food. Each histamine measure was expressed as $\times 10^{-3}$ ppm. During all experimental processes, three replicate measures per treatment food-combination were conducted.

\section{Statistical analysis}

All experimental values were expressed as means \pm standard deviations of three replicates. The statistical significance of any differences between data was assessed by analysis of variance (ANOVA), followed by the Dunnett's test or Tukey's test. $p$-values $<0.05$ were considered to be statistically significant. All statistical analyses were conducted using PASW Statistics ver. 18.0 (IBM Co., Armonk, NY, USA).

\section{RESULTS}

\section{Fishery products and processed marine products}

Foods in the fishery products and processed marine products group were cooked according to the representative cooking methods: frying, grilling or boiling. Then, we measured the histamine levels in cooked foods. Fig. 1 shows the histamine levels of the cooked fishery products and processed marine products.

Fried dried anchovy $\left(13,347 \pm 10,738.81 \times 10^{-3} \mathrm{ppm}\right)$ showed the highest histamine level in this group, followed by grilled dried anchovy $\left(2,669 \pm 1,538.20 \times 10^{-3} \mathrm{ppm}\right)$. In the case of dried anchovy, the histamine level increased after frying $\left(13,347 \pm 10,738.81 \times 10^{-3} \mathrm{ppm}\right)$, grilling $(2,669 \pm$ $\left.1,538.20 \times 10^{-3} \mathrm{ppm}\right)$, and boiling $\left(105 \pm 41.94 \times 10^{-3} \mathrm{ppm}\right)$. When fried, the histamine level of dried anchovy showed a $>200$-fold increase than when uncooked, and when grilled, it showed about a 45 -fold increase. When boiled,

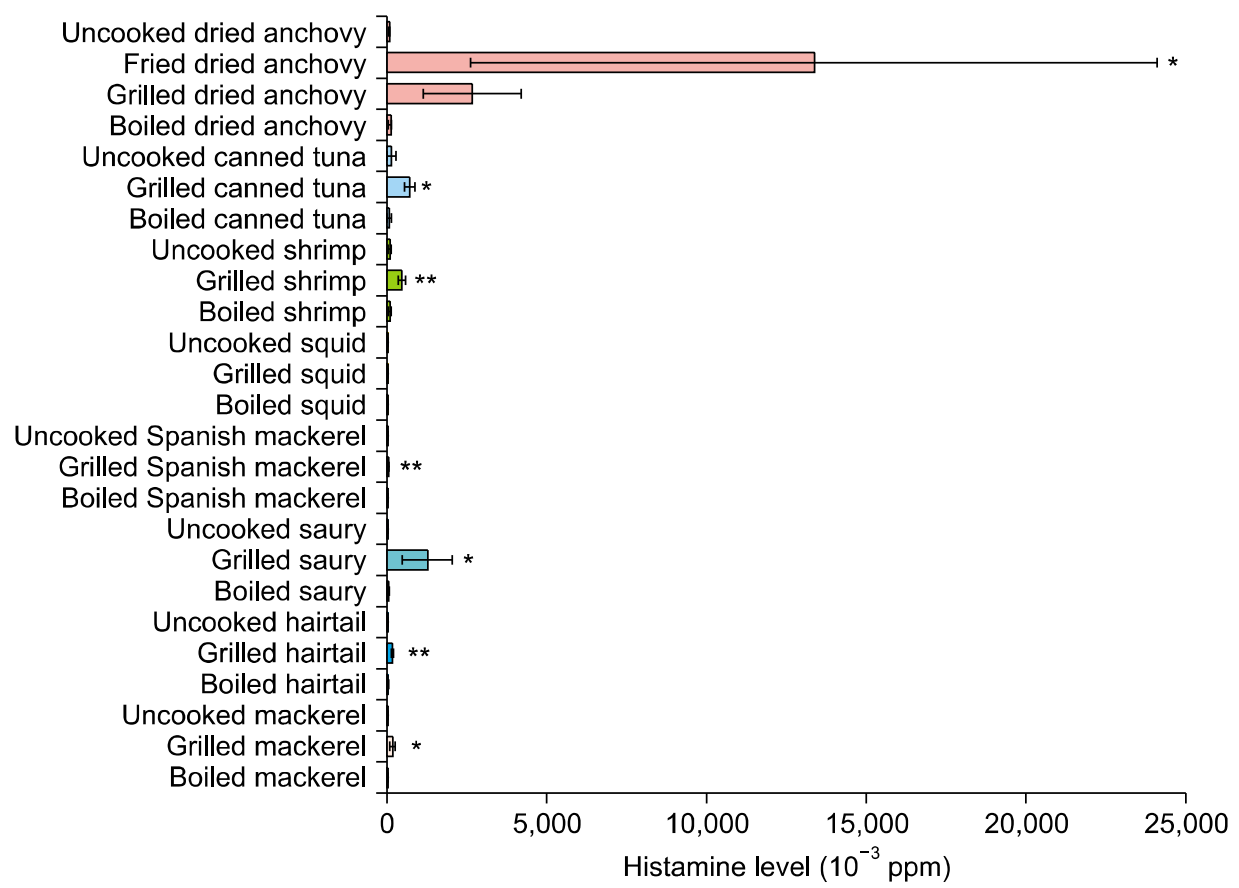

Fig. 1. Histamine level in fishery products and processed marine products. Data are presented as the mean \pm standard deviation $(\mathrm{n}=3) .{ }^{*} p$ $<0.05$ and ${ }^{* *} p<0.01$ compared to uncooked food. The statistical significance of any difference between data was assessed by analysis of variance (ANOVA), followed by Dunnett's or Tukey's test. $p$-values $<0.05$ were considered to be statistically significant. 
the histamine level increased only 2-fold. In the case of tuna, the histamine level was increased about 5 -fold by grilling $\left(717 \pm 161.52 \times 10^{-3} \mathrm{ppm}\right)$, but decreased slightly after boiling $\left(78 \pm 63.55 \times 10^{-3} \mathrm{ppm}\right)$. For shrimp, saury, hairtail, and mackerel, the histamine level slightly increased or was not changed, by boiling. However, grilling caused it to increase remarkably ( $8 \sim 56$ fold). The histamine level of Spanish mackerel was increased about 2-fold by grilling, while there was no distinctive change in histamine level from boiling. The method of cooking caused no distinctive changes in the histamine level of squid. Taken together, grilling in most of the fishery products and processed marine products group increased the histamine level more than boiling did. Also, regarding frying, only dried anchovy in the category of fishery/processed marine products was fried in our study.

\section{Meat, processed meat and egg}

Foods in the meat, processed meat and egg group were cooked by frying, grilling, or boiling; then we measured the histamine levels in the cooked foods (Fig. 2). Grilled pork showed the highest histamine level in this group $\left(1,146 \pm 1,016.90 \times 10^{-3} \mathrm{ppm}\right)$. For pork and chicken, the histamine level was increased about 1.5 -fold by grilling, but was decreased $10 \% \sim 20 \%$ by boiling. The histamine level of beef changed less than of other cooked meats, grilling caused a 1.8-fold increase, while there was no distinctive change due to boiling. In the case of sausage, the histamine level was slightly increased (1.03-fold) by grilling $\left(502 \pm 77.38 \times 10^{-3} \mathrm{ppm}\right)$, but decreased $60 \%$ after boiling $\left(193 \pm 20.42 \times 10^{-3} \mathrm{ppm}\right)$. The histamine level of ham was increased about 1.4-fold by grilling $(283 \pm 142.90$ $\left.\times 10^{-3} \mathrm{ppm}\right)$, but decreased $60 \%$ after boiling $(79 \pm 19.52$ $\left.\times 10^{-3} \mathrm{ppm}\right)$. These results showed that grilling increased the histamine level of most meat and processed meat, while boiling decreased their histamine levels.

For eggs, there was not much difference in histamine level in relation to cooking by boiling $\left(12 \pm 1.73 \times 10^{-3} \mathrm{ppm}\right)$ or frying $\left(11 \pm 1 \times 10^{-3} \mathrm{ppm}\right)$.

\section{Vegetables}

Foods in the vegetable group were cooked by frying or blanching. Fig. 3 showed the histamine levels of cooked vegetables. For onions and spinach, no distinct difference in histamine level resulted from these cooking methods. In the case of carrots, the histamine level was increased 2.5 -fold by frying $\left(31 \pm 6 \times 10^{-3} \mathrm{ppm}\right)$. The histamine level of laver seaweed was increased about 4-fold by frying $\left(168 \pm 39.69 \times 10^{-3} \mathrm{ppm}\right)$. Frying increased the histamine level in carrots and laver seaweed.

\section{Fermented pastes and dairy products}

Fermented pastes, including soybean paste $(1,164 \pm 79$ $\left.\times 10^{-3} \mathrm{ppm}\right)$ and red pepper paste $\left(1,448 \pm 98 \times 10^{-3} \mathrm{ppm}\right)$, showed high histamine, but not much difference in histamine level was caused by boiling. Salty fermented anchovies showed a much higher histamine level $(1,157 \pm 313$ $\left.\times 10^{-3} \mathrm{ppm}\right)$ than did dried anchovies $\left(59 \pm 11 \times 10^{-3} \mathrm{ppm}\right)$. Additionally, we compared the histamine levels in fermented and fresh vegetables. Kimchi, including both fermented cabbage $\left(378 \pm 22 \times 10^{-3} \mathrm{ppm}\right)$ and radish $(500 \pm 74$ $\times 10^{-3} \mathrm{ppm}$ ), showed $30 \sim 50$-fold increase in histamine levels compared to fresh cabbage $\left(11 \pm 1 \times 10^{-3} \mathrm{ppm}\right)$ and fresh radish $\left(10 \pm 2 \times 10^{-3} \mathrm{ppm}\right)$.

The histamine level of dairy cheese $\left(418 \pm 85 \times 10^{-3} \mathrm{ppm}\right)$ was significantly 20 -fold greater than that of fresh milk $\left(12 \pm 7 \times 10^{-3}\right.$ ppm) (Fig. 4).

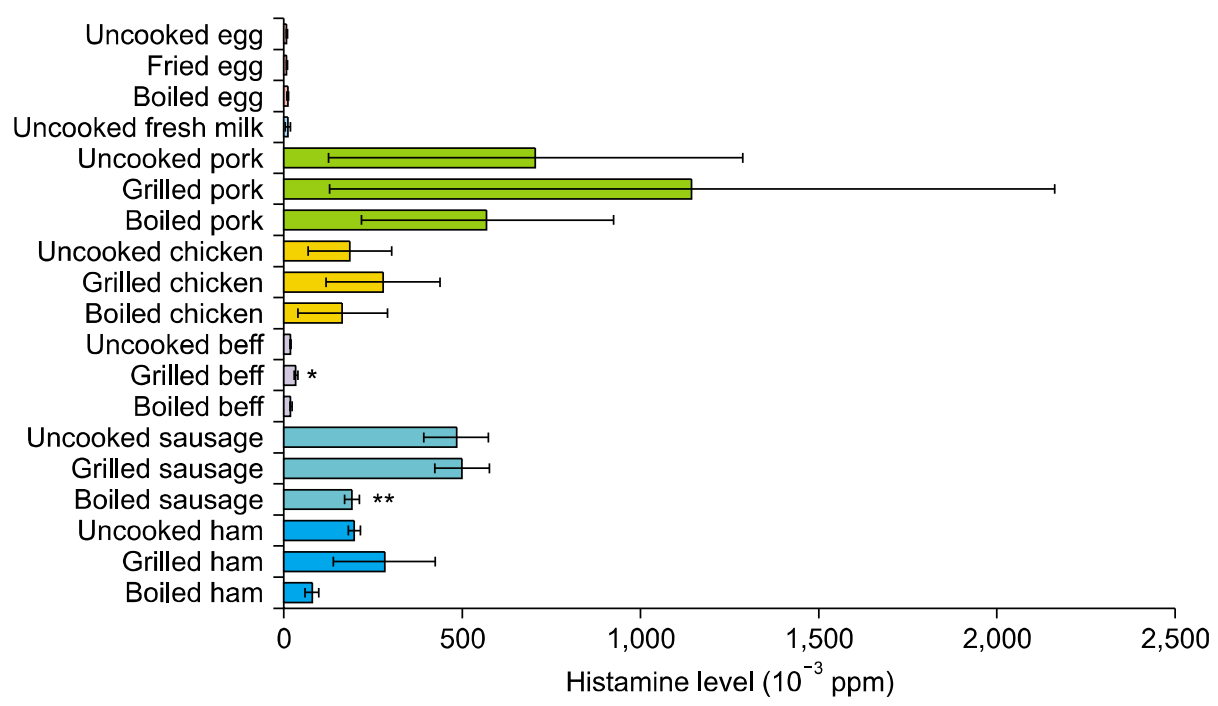

Fig. 2. Histamine level in eggs, milk, meat, and processed meat. Data are presented as the mean \pm standard deviation $(\mathrm{n}=3) .{ }^{*} p<0.05$ and ${ }^{* *} p<$ 0.01 compared to uncooked food. The statistical significance of any difference between data was assessed by analysis of variance (ANOVA), followed by Dunnett's or Tukey's test. $p$-values < $<0.05$ were considered to be statistically significant. 


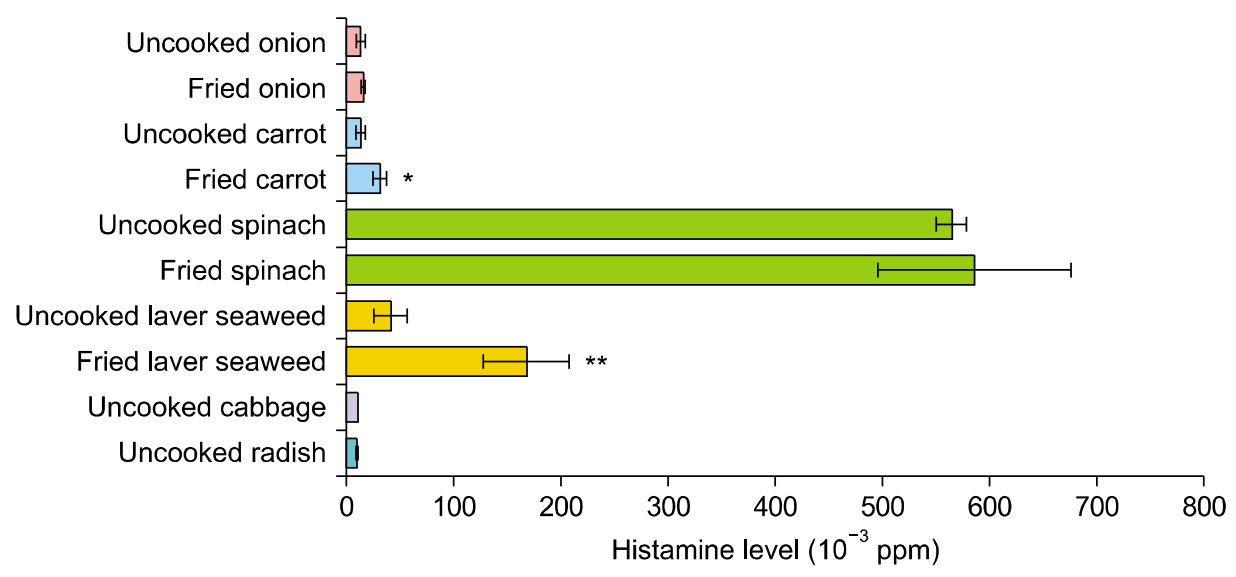

Fig. 3. Histamine level in vegetables. Data are presented as the mean \pm standard deviation $(\mathrm{n}=3)$. ${ }^{*} p<0.05$ and $* * p<0.01$ compared to uncooked food. The statistical significance of any difference between data was assessed by analysis of variance (ANOVA), followed by Dunnett's or Tukey's test. $p$-values $<0.05$ were considered to be statistically significant.

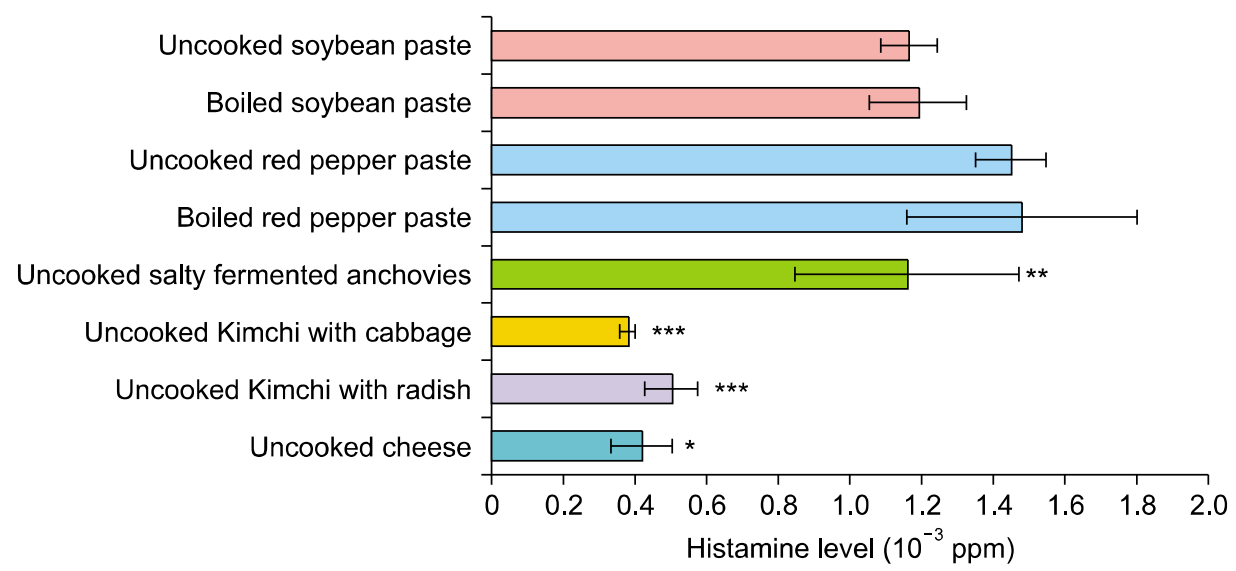

Fig. 4. Histamine level in fermented paste and dairy products. Data are presented as the mean $\pm \operatorname{standard~deviation~}(\mathrm{n}=3)$. ${ }^{*} p<0.05$, ${ }^{* *} p<0.01$, and ${ }^{* * *} p<0.001$ compared to uncooked food. This means that uncooked cabbage Kimchi, uncooked radish Kimchi, and uncooked cheese were compared to fresh cabbage, radish, and milk, respectively. The statistical significance of any difference between data was assessed by analysis of variance (ANOVA), followed by Dunnett's or Tukey's test. $p$-values $<0.05$ were considered to be statistically significant.

\section{DISCUSSION}

Biogenic amines are organic, basic nitrogenous compounds of low molecular weight, usually formed by decarboxylation of free amino acids. In addition to their well-known occurrence and important role as endogenous regulators of several human physiological processes, biogenic amines occur in many different foods and beverages. Their concentrations vary extensively, not only between different food varieties, but also within the varieties themselves $^{19}$. It has been known for some time that uptake of biogenic amines from foods can have profound effects on human health and well-being ${ }^{20}$. The most frequent foodborne intoxications and intolerance caused by biogenic amines, involve histamine. Whereas high histamine consumption causes life threatening intoxication, lower amounts can lead to headache, nausea, hot flushes, skin rashes, sweating, respiratory distress, and cardiac and intestinal problems to histamine-sensitive people ${ }^{3,4}$.

Most foods are usually eaten after cooking in various ways and we eat cooked food more often than raw. However, data on the effect of cooking on the histamine content of foods are still incomplete ${ }^{21-23}$. In the present study, we evaluated the effect of cooking practices on the concentration of histamine in foods by comparing the histamine levels between raw and cooked foods. The histamine level of most fishery products and processed marine products, except for squid, was increased by grilling, and it seems that most of them increased greatly. Regarding frying, only dried anchovy in the category of fishery/processed marine products was fried in our study. Therefore, further study will be needed to determine the effect of frying on the lev- 
el of histamine in other kinds of food in the category of fishery/processed marine products. However, in this group, boiling had little influence on histamine level, although it did increase very slightly. The histamine level of meat and processed meat was also increased by grilling, but not as much as fishery products and processed marine products. Meanwhile, boiling of most meats decreased the histamine level. For eggs, no significant changes in histamine level were observed in relation to frying and boiling. Fried vegetables had higher histamine levels than raw vegetables. As expected, the fermented food showed generally high histamine level. However, fermented pastes showed no changes in histamine level by boiling.

Pre-requisites for the formation of histamine are availability of free amino acid, such as histidine, presence of decarboxylase active microorganisms, and favorable conditions for decarboxylation of amino acids ${ }^{2}$. Scombroid species of fish have naturally high levels of histidine in their muscle tissue, which can be used by microorganisms capable of producing the enzyme histidine decarboxylase, to convert histidine to histamine during growth ${ }^{24,25}$. Evidently, food rich in free histidine, such as some fish species (anchovies, scombroid fish, and herring) are potentially more likely to contain high histamine levels ${ }^{26}$. In our study, fishery group foods in their raw forms showed high histamine levels. High free histidine level and availability in the food is thought to result in high histamine level in food.

In our study, as expected, fermented foods, including Kimchi, soybean paste, and red pepper paste, showed high histamine levels. Kimchi, soybean paste, and red pepper paste are traditional foods that Koreans enjoy eating, and there are some studies on histamine levels of these fermented foods ${ }^{27,28}$. Kimchi is made by fermenting vegetables, such as salted cabbage or radish, with a number of other ingredients, including such as red pepper powder, garlic, and ginger. It is fermented by lactic acid bacteria at low temperatures, ensuring proper ripening and preservation ${ }^{29}$. Soybean paste is generally made by additional fermentation of the solid material that separates from a mixture of Meju (fermented soybean lumps) and Ganjang fermented soy source). The latter is prepared by soaking Meju in solar salt solution (approximately 16\% $18 \%[\mathrm{w} / \mathrm{v}]$ salts) for approximately $1 \sim 2$ months $^{30,31}$. Red pepper paste is produced by fermenting powdered red pepper combined with powdered Meju (fermented soybean powder), salt, malt-digested rice syrup, and rice flour for about six months ${ }^{32,33}$. The fermentation process extends the storage period while increasing the bioavailability of bioactive ingredients such as free amino acids, peptides, alcohols, organic acids, capsaicin, and fla- vonoids ${ }^{33}$. In fermented foods the contaminating microflora is mainly responsible for the generation of increasing histamine levels ${ }^{34-38}$. Besides that, salt, sugar, red pepper or food additives can affect the level of histamine ${ }^{39,40}$.

Cooking causes inactivation of histamine-producing spoilage bacteria. However, histamine is heat resistant, so it can remain intact in cooked products ${ }^{41}$. Therefore, if histamine is produced in the product before cooking, it can cause illness if it presents in the product at toxic concentrations. The degradation change of histamine by a heating process, such as frying, has rarely been reported ${ }^{38}$. In our study, heating processes, such as grilling and frying, increased the histamine levels in foods. The possible reason for these changes may have been that the moisture lost by evaporation during grilling or frying could cause the histamine concentration to increase. This also showed how the histamine level of boiling in some foods decreased. Previous study found that the food absorbed water while boiling, so the histamine concentration was decreased by dilution ${ }^{36}$. The cellular components of foods might be softened and broken by boiling and consequently released into the boiling water. However, further studies will be needed to determine the losses from foods due to cooking (e.g., moisture loss) to confirm the precise mechanism of effect of cooking method on the histamine level in foods.

Also, another possible reason for the differences is that the histamine formation is affected by histidine decarboxylase activity. Histidine decarboxylase is the enzyme that converts the histidine in food into histamine. The formation of histamine in food requires the presence of histidine decarboxylase-positive microorganisms, in conjunction with conditions allowing the growth and enzyme activity of these bacteria ${ }^{42}$. It is known that there are several factors (e.g., $\mathrm{pH}$, temperature, and $\mathrm{NaCl}$ concentration) that affect histidine decarboxylase activity ${ }^{14,43,44}$. This enzyme activity increased with increasing temperature to $30^{\circ} \mathrm{C} \sim 40^{\circ} \mathrm{C}$ and decreased above $50^{\circ} \mathrm{C}$. Although histidine decarboxylase activity decreased at high temperature, histamine production would continue until the enzyme became inactive $^{44}$. Histamine, once formed in food, is heat stable even if heating inactivates both the enzyme and the source microorganisms ${ }^{21,34,35}$. Consequently, during heat treatment the histamine in food would accumulate continuously until the enzyme was inactive. This may explain why the histamine level was increased by heat treatment of most seafood and meat in our study. Boiling is also one of the heat treatments that elevated the histamine level, but the effect could be reduced due to dilution, as mentioned. However, further studies monitoring the levels of histamine-producing bacteria and histidine-decarboxylase 
activity will also be needed to confirm this mechanism for the change of the histamine levels in cooked foods.

For eggs, no significant changes in histamine level were observed in relation to cooking methods. The change in the water content of eggs was reported to be minimal after boiling and frying, which may account for the small change in the histamine level after cooking. In addition, because the histamine level was relatively low for eggs $\left(10 \pm 2 \times 10^{-3} \mathrm{ppm}\right)$, there is a possibility of detection failure because the changes after different cooking methods could also be too trivial to be measured ${ }^{45}$.

When interpreting the results for frying, the influence of soybean oil should be considered. However, because soy bean oil has a relatively low histamine level $\left(14 \times 10^{-3}\right.$ ppm), it is thought to have little effect on the level of histamine in fried foods.

Numerous factors during manufacture and distribution should be comsidered to affect on histamine contents in food. Previous study demonstrated that large variations in the amine content were found in retail Belgian sausages, and that these were related to the method of manufacture $^{46}$. Furthermore, wide variations were observed in the amine content of different batches of the same commercial brand of fermented Spanish products ${ }^{47}$. Previous studies reported that fish could be contaminated with histamine-producing microorganisms during postharvest handling of the fish $^{24}$. Fresh scombrotoxin-forming fish contain negligible amounts of histamine ( $<1 \mathrm{ppm})$, but high levels of histamine occur when harvested fish are held at temperatures above $15^{\circ} \mathrm{C}$ for several hours, permitting spoilage microorganisms to grow ${ }^{24,48,49}$. Several studies clearly show that immediate storage on ice drastically decreases the rate of histamine formation ${ }^{50-52}$, Also, high levels of histamine in commercially produced canned-fish products have occurred and are primarily due to temperature abuse before canning ${ }^{53}$. Therefore, the histamine contents in foodstuff can be affected by numerous extrinsic factors during manufacture and distribution. Confirming the variability of histamine level regarding manufacture and distribution will require examining the histamine content in more food items, in similar foods from more manufacturers, and in similar foods distributed in other ways.

The cooking time is another characteristic of a cooking method. The effect of cooking time on the histamine level should be considered. However, in our study, we created some variation in cooking time in the same cooking method. Fishery products and processed marine products, eggs, meat, and processed meat were grilled, or boiled until well done. It was considered meaningful to measure histamine levels of foods in actual ready-to-eat condition.
Because the time needed to cook each food to reach that condition is different, we could not make the cooking time uniform.

In our study, we determined the histamine levels in raw and cooked foods. Because the levels detected in raw and cooked food in this study were significantly lower that the toxic level set by Food and Drug Administration (50 ppm), these levels or the increase caused by cooking could not induce food poisoning or intolerance. However, the susceptibility to histamine varies according to the enteral environment and DAO activity of each individual ${ }^{5}$. Sensitive persons, with insufficient DAO activity, could suffer from numerous undesirable reactions after intake of foods containing low amounts of histamine. We speculated that using the fresh foods with good pre-cooking condition could affect the low level of histamines in most foods of our study.

There are several limitations of this work and this article. The priority of the food items and cooking methods used in this work was based on their frequency of utilization by Koreans. Therefore, the outcome of this article would not definitely reflect the dietary characteristics of other (foreign) countries.

Also, foodstuffs can be affected by numerous extrinsic factors during manufacture and distribution; so variability might exist among the same products. Also, only a few food items in each food category were used in this article; so it might be hard to generalize the results. It is necessary to confirm the difference in histamine levels related to more cooking methods and in more foods from more manufacturers.

To the best of our knowledge, there are no previous studies about direct comparison between cooking methods; so it is meaningful to make lists of the histamine levels of various cooked foods. We also tried to find some tendencies between the cooking methods regarding the level of histamine. In our study, it seems that grilled and fermented food showed increased histamine levels. However, due to the wide variation of basal histamine levels, there was no statistical significance in the differences between any of the food items. Also, among the categories of food items, the tendencies were a bit different; so it was hard to perform direct comparison between the cooking methods.

To conclude, this study showed that the histamine level in foods can change according to the cooking method used to prepare it. In our study, frying and grilling seems to increase histamine level in foods, whereas boiling had little influence or even decreased it. Considering our results, boiling, compared with frying, grilling and fermenting was found to be a more effective method for reducing the histamine content. This study could be beneficial for se- 
lection of cooking practice in histamine-sensitive people with food intolerance, by providing data for reducing the histamine level in their diets.

\section{ACKNOWLEDGMENT}

This work was supported by Hallym University Research Fund 2014 (HURF-2014-58).

\section{CONFLICTS OF INTEREST}

The authors have nothing to disclose.

\section{REFERENCES}

1. Fogel WA, Lewinski A, Jochem J. Histamine in food: is there anything to worry about? Biochem Soc Trans 2007;35:349-352.

2. Bodmer S, Imark C, Kneubühl M. Biogenic amines in foods: histamine and food processing. Inflamm Res 1999;48:296300.

3. Taylor SL. Histamine food poisoning: toxicology and clinical aspects. Crit Rev Toxicol 1986;17:91-128.

4. Taylor SL, Stratton JE, Nordlee JA. Histamine poisoning (scombroid fish poisoning): an allergy-like intoxication. J Toxicol Clin Toxicol 1989;27:225-240.

5. Maintz L, Novak N. Histamine and histamine intolerance. Am J Clin Nutr 2007;85:1185-1196.

6. Cho HJ, Cho SI, Kim HO, Park CW, Lee $\mathrm{CH}$. Lack of association of plasma histamine with diamine oxidase in chronic idiopathic urticaria. Ann Dermatol 2013;25:189195.

7. Maintz L, Benfadal S, Allam JP, Hagemann T, Fimmers R, Novak $\mathrm{N}$. Evidence for a reduced histamine degradation capacity in a subgroup of patients with atopic eczema. J Allergy Clin Immunol 2006;117:1106-1112.

8. Maintz L, Schwarzer V, Bieber T, van der Ven K, Novak N. Effects of histamine and diamine oxidase activities on pregnancy: a critical review. Hum Reprod Update 2008;14: 485-495.

9. Ruan P, Gong ZJ, Zhang QR. Changes of plasma $\mathrm{D}(-)-$ lactate, diamine oxidase and endotoxin in patients with liver cirrhosis. Hepatobiliary Pancreat Dis Int 2004;3:58-61.

10. Takimoto Y, Yoshiuchi K, Shimodaira S, Akabayashi A. Diamine oxidase activity levels in anorexia nervosa. Int J Eat Disord 2014;47:203-205.

11. Honzawa $Y$, Nakase $H$, Matsuura $M$, Chiba T. Clinical significance of serum diamine oxidase activity in inflammatory bowel disease: Importance of evaluation of small intestinal permeability. Inflamm Bowel Dis 2011;17:E23-E25.

12. Miyoshi J, Miyamoto H, Goji T, Taniguchi T, Tomonari T, Sogabe $M$, et al. Serum diamine oxidase activity as a predictor of gastrointestinal toxicity and malnutrition due to anticancer drugs. J Gastroenterol Hepatol 2015;30:15821590.
13. Wöhrl S, Hemmer W, Focke M, Rappersberger K, Jarisch R. Histamine intolerance-like symptoms in healthy volunteers after oral provocation with liquid histamine. Allergy Asthma Proc 2004;25:305-311.

14. Naila A, Flint S, Fletcher G, Bremer P, Meerdink G. Control of biogenic amines in food--existing and emerging approaches. J Food Sci 2010;75:R139-R150.

15. Wendakoon CN, Sakaguchi M. Inhibition of amino acid decarboxylase activity of Enterobacter aerogenes by active components in spices. J Food Prot 1995;58:280-283.

16. Nam H, Lee K, Myung C, Rhee J, Lee YC, Hong CS. Analysis on the contents of histamine in Korean foods. J Soc Food Sci 1996;12:487-492.

17. Choi JH, Park CW, Lee CH. A study of histamine content in food in Korea. Korean J Dermatol 2007;45:768-771.

18. Diel E, Bayas N, Stibbe A, Müller S, Bott A, Schrimpf D, Diel F. Histamine containing food: Establishment of a German Food Intolerance Databank (NFID). Inflamm Res 1997;46(Suppl 1):87-88.

19. Silla Santos $\mathbf{M H}$. Biogenic amines: their importance in foods. Int J Food Microbiol 1996;29:213-231.

20. Chung BY, Cho SI, Ahn IS, Lee HB, Kim HO, Park CW, et al. Treatment of atopic dermatitis with a low-histamine diet. Ann Dermatol 2011;23 Suppl 1:S91-S95.

21. Enache E, Kataoka A, Black DG, Weddig L, Hayman M, Bjornsdottir-Butler K. Heat resistance of histamine-producing bacteria in irradiated tuna loins. J Food Prot 2013;76: 1608-1614.

22. Fletcher GC, Summers G, van Veghel PW. Levels of histamine and histamine-producing bacteria in smoked fish from New Zealand markets. J Food Prot 1998;61:10641070.

23. Li L, Wang $P, X u$ X, Zhou G. Influence of various cooking methods on the concentrations of volatile $\mathrm{N}$-nitrosamines and biogenic amines in dry-cured sausages. J Food Sci 2012;77:C560-C565.

24. Mavromatis P, Quantick PC. Modification of Niven's medium for the enumeration of histamine-forming bacteria and discussion of the parameters associated with its use. J Food Prot 2002;65:546-551.

25. Omura $Y$, Price $R$, Olcott $H$. Histamine-forming bacteria isolated from spoiled skipjack tuna and jack mackerel. J Food Sci 1978;43:1779-1781.

26. Hungerford JM. Scombroid poisoning: a review. Toxicon 2010;56:231-243.

27. Kung HF, Tsai $\mathrm{YH}$, Wei $\mathrm{Cl}$. Histamine and other biogenic amines and histamine-forming bacteria in miso products. Food Chem 2007;101:351-356.

28. Tsai $\mathrm{YH}$, Kung HF, Lin QL, Hwang JH, Cheng $\mathrm{SH}$, Wei $\mathrm{Cl}$, et al. Occurrence of histamine and histamine-forming bacteria in kimchi products in Taiwan. Food Chem 2005; 90:635-641.

29. Lee ME, Jang JY, Lee JH, Park HW, Choi HJ, Kim TW. Starter cultures for kimchi fermentation. J Microbiol Biotechnol 2015;25:559-568.

30. Jung JY, Lee SH, Jeon CO. Microbial community dynamics during fermentation of doenjang-meju, traditional Korean 
fermented soybean. Int J Food Microbiol 2014;185:112120.

31. Jeon HH, Jung JY, Chun BH, Kim MD, Baek SY, Moon JY, et al. Screening and characterization of potential bacillus starter cultures for fermenting low-salt soybean paste (Doenjang). J Microbiol Biotechnol 2016;26:666-674.

32. Oh JY, Kim YS, Shin DH. Changes in microorganisms, enzyme activities, and gas formation by the addition of mustard powder on kochujang with different salt concentration. Food Sci Biotechnol 2006;15:298-302.

33. Cha YS, Kim SR, Yang JA, Back HI, Kim MG, Jung SJ, et al. Kochujang, fermented soybean-based red pepper paste, decreases visceral fat and improves blood lipid profiles in overweight adults. Nutr Metab (Lond) 2013;10:24.

34. Visciano P, Schirone M, Tofalo R, Suzzi G. Histamine poisoning and control measures in fish and fishery products. Front Microbiol 2014;5:500.

35. Lehane L. Update on histamine fish poisoning. Med J Aust 2000;173:149-152.

36. Beutling D. Biogenic amines in nutrition. Arch Lebensmittelhyg 1996;47:97-102.

37. Stratton JE, Hutkins RW, Taylor SL. Biogenic amines in cheese and other fermented foods: a review. J Food Prot 1991; 54:460-470.

38. Lee YC, Lin CM, Huang CY, Huang YL, Chen HC, Huang $\mathrm{TC}$, et al. Determination and frying loss of histamine in striped marlin fillets implicated in a foodborne poisoning. J Food Prot 2013;76:860-866.

39. Mah JH, Hwang HJ. Effects of food additives on biogenic amine formation in Myeolchi-jeot, a salted and fermented anchovy (Engraulis japonicus). Food Chem 2009;114:168173.

40. Roseiro C, Santos C, Sol M, Silva L, Fernandes I. Prevalence of biogenic amines during ripening of a traditional dry fermented pork sausage and its relation to the amount of sodium chloride added. Meat Sci 2006;74:557-563.

41. López-Sabater EI, Rodríguez-Jerez JJ, Roig-Sagues AX, Mora-Ventura M. Bacteriological quality of tuna fish (Thunnus thynnus) destined for canning: effect of tuna handling on presence of histidine decarboxylase bacteria and histamine level. J Food Prot 1994;57:318-323.

42. Sattler J, Häfner D, Klotter HJ, Lorenz W, Wagner PK. Food-induced histaminosis as an epidemiological problem: plasma histamine elevation and haemodynamic alterations after oral histamine administration and blockade of diamine oxidase (DAO). Agents Actions 1988;23:361-365.

43. Tabanelli G, Torriani S, Rossi F, Rizzotti L, Gardini F. Effect of chemico-physical parameters on the histidine decarboxylase (HdcA) enzymatic activity in Streptococcus thermophilus PRI60. J Food Sci 2012;77:M231-M237.

44. Kanki M, Yoda T, Tsukamoto T, Baba E. Histidine decarboxylases and their role in accumulation of histamine in tuna and dried saury. Appl Environ Microbiol 2007;73: 1467-1473.

45. Roe M, Pinchen $\mathrm{H}$, Church S, Finglas P. Nutrient analysis of eggs. Norwich: Institute of Food Research, Norwich Research Park, 2012.

46. Vandekerckhove P. Amines in dry fermented sausage. J Food Sci 1977;42:283-285.

47. Hernández-Jover T, Izquierdo-Pulido M, Veciana-Nogués MT, Mariné-Font A, Vidal-Carou MC. Biogenic amine and polyamine contents in meat and meat products. J Agric Food Chem 1997;45:2098-2102.

48. Gilbert RJ, Hobbs G, Murray CK, Cruickshank JG, Young SE. Scombrotoxic fish poisoning: features of the first 50 incidents to be reported in Britain (1976-9). Br Med J 1980;281:71-72.

49. Bjornsdottir-Butler K, Jones JL, Benner RA Jr, Burkhardt W 3rd. Quantification of total and specific gram-negative histamine-producing bacteria species in fish using an MPN real-time PCR method. Food Microbiol 2011;28:1284-1292.

50. Hongpattarakere T, Buntin N, Nuylert A. Histamine development and bacterial diversity in microbiallychallenged tonggol (Thunnus tonggol) under temperature abuse during canning manufacture. J Food Sci Technol 2016;53:245-256.

51. Economou V, Brett MM, Papadopoulou C, Frillingos S, Nichols T. Changes in histamine and microbiological analyses in fresh and frozen tuna muscle during temperature abuse. Food Addit Contam 2007;24:820-832.

52. Rossano R, Mastrangelo L, Ungaro N, Riccio P. Influence of storage temperature and freezing time on histamine level in the European anchovy Engraulis encrasicholus (L., 1758): A study by capillary electrophoresis. J Chromatogr B Analyt Technol Biomed Life Sci 2006;830:161-164.

53. Sánchez-Guerrero IM, Vidal JB, Escudero AI. Scombroid fish poisoning: a potentially life-threatening allergic-like reaction. J Allergy Clin Immunol 1997;100:433-434. 